\title{
molecules
}

ISSN 1420-3049

www.mdpi.com/journal/molecules

Review

\section{Cardanol-Based Materials as Natural Precursors for Olefin Metathesis}

\author{
Giuseppe Vasapollo *, Giuseppe Mele and Roberta Del Sole \\ Department of Engineering for Innovation, University of Salento, Arnesano Street, Lecce 73100, Italy \\ * Author to whom correspondence should be addressed; E-Mail: giuseppe.vasapollo@unisalento.it; \\ Tel.: +39-0832-297252; Fax: +39-0832-297733.
}

Received: 4 May 2011; in revised form: 8 July 2011 / Accepted: 12 July 2011 /

Published: 11 August 2011

\begin{abstract}
Cardanol is a renewable, low cost natural material, widely available as a by-product of the cashew industry. It is a mixture of 3- $n$-pentadecylphenol, 3-(pentadeca-8enyl)phenol, 3-(pentadeca-8,11-dienyl)phenol and 3-(pentadeca-8,11,14-trienyl)phenol. Olefin metathesis $(\mathrm{OM})$ reaction on cardanol is an important class of reactions that allows for the synthesis of new olefins that are sometime impossible to prepare via other methods. The application of this natural and renewable material to both academic and industrial research will be discussed.
\end{abstract}

Keywords: Grubbs catalysts; metathesis; pentadecylphenol; cardanol; porphyrins; metallo-porphyrins; fullerenes; fulleropyrrolidines

\section{Introduction}

In recent years, among other natural compounds, the use of cardanol to form various new compounds and hybrid compounds has attracted the attention of scientists [1-17]. Cardanol is a renewable and inexpensive organic natural resource that is easily obtained via the vacuum distillation of roasted cashew nut shell liquid (CNSL) obtained from the spongy mesocarp of cashew nut shells.

CNSL is a mixture of cardanol, cardol and 2-methylcardol. All these compounds possess a characteristic long alkyl chain in the meta position [1-4]. Cardanol is the main component (about 84\%) of CNSL and is itself a mixture of 3- $n$-pentadecylphenol, 3-(-pentadeca-8-enyl)phenol, 3-(pentadeca8,11-dienyl)phenol and 3-(pentadeca-8,11,14-trienyl)phenol (Figure 1). Depending on the purification- 
distillation of cardanol, the monoolefinic 3-(-pentadeca-8-enyl)phenol, can be the main component, accounting for almost $95 \%$ on the total; hence, in this work, the term cardanol refers to this monoolefin.

Figure 1. Constituents of technical-grade cashew nut shell liquid.<smiles>[R]c1cccc(O)c1</smiles>

cardanol 1<smiles>[R]c1cc(O)cc(O)c1</smiles>

cardol<smiles>[R]c1cc(C)cc(O)c1</smiles>

2-methylcardol

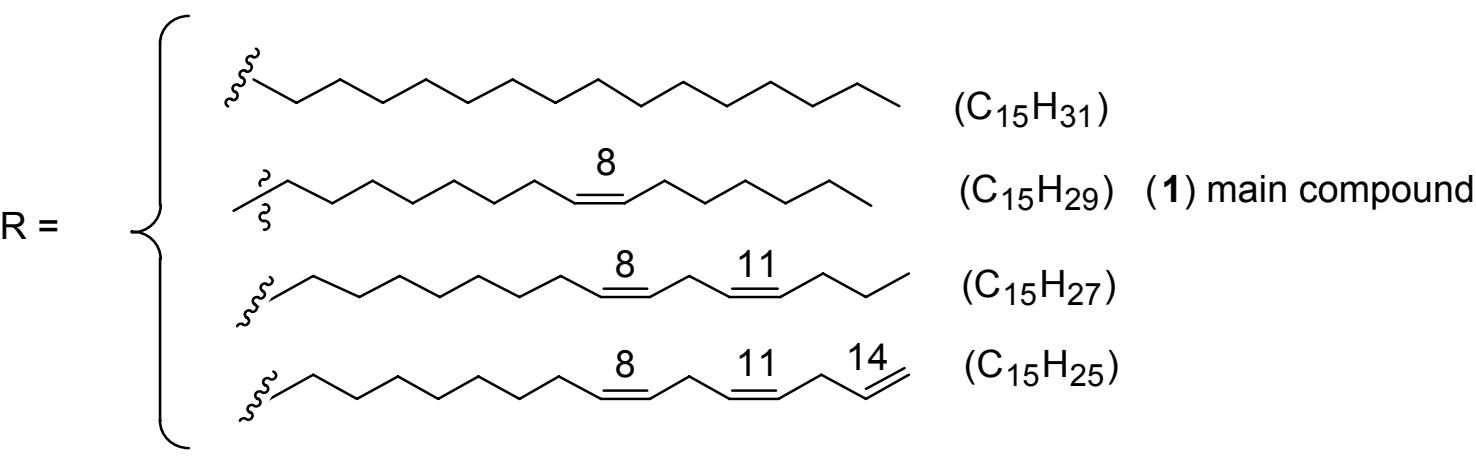

The preparation of fine chemicals from natural and renewable materials has become an attractive topic of research, particularly when the purpose is to recycle the huge amount of agro-industrial wastes to produce, through environmentally sustainable processes, fine chemicals which can be used for different purposes. The extraction of fine chemicals from wastes, such as cardanol, is an old concept. In fact, the phrase "from waste to value", which means making useful chemical products using the wastes of industry is a well known one. Further, cardanol has a special and unique characteristic: It contains in the meta position of the phenolic ring a long alkyl chain that confers attractive properties to cardanol derivatives such as good processability and high solubility in organic solvents; but, also the possibility to influence many chemical transformation introducing novel functionalities [3-14].

This paper presents an overview of the developments in olefin metathesis involving cardanol or cardanol-derived molecules for the preparation of new fine chemicals as well new hybrid functional materials, such as porphyrins, phthalocyanines and fullerenes.

\section{Cardanol: Description and Oil Characteristic}

Cardanol is easily obtained by vacuum distillation of CNSL, which is a by-product of the cashew industry. Commercially available CNSL contains a mixture of cardanol (1), cardol and 2-methylcardol (Figure 1) in approximately 84, 11 and 5\%, respectively. As reported in the literature, by further re-distillation of the liquid, it is possible to obtain a mixture that is rich $(90 \%$ on average) in the monoolefinic and diolefinic components, together with minor amounts of the triolefin and $3-n$-pentadecylphenol. The average composition of the mixture is: $20 \%-30 \% 3$ - $n$-pentadecyl phenol, 70\%-80\% 3-(pentadeca-8-enyl) phenol (1), nearly 5\% 3-(pentadeca-8,11-dienyl) phenol and less than 
5\% 3-(pentadeca-8,11,14-trienyl) phenol. Cis and trans isomers of each component are present in the mixture, but usually the cis component is the major one. This mixture can be further purified by successive re-distillation/chromatography. In this way, the monoolefin component, 3-(penta-deca-8enyl)phenol was obtained almost pure. For simplicity, this isolate will hereon be referred to as "cardanol" in this work. Several types of chemical reactions can be carried out involving the benzene ring, the olefin or the hydroxyl group (Figure 2).

Figure 2. Possible sites for functionalization of the cardanol molecule.

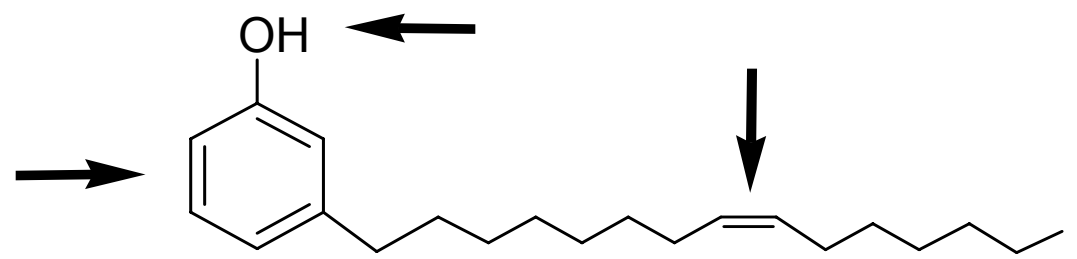

The presence olefin group in the long chain attached to the meta position of the phenolic ring allows for the possibility for generating new cardanol-based compounds via metathesis reactions.

\section{Preparation of Cardanol-Based Derivatives}

Schemes 1 and 2 depict the syntheses of several cardanol-based derivatives that have been used as precursors for metathesis reactions.

Scheme 1. Molecular structure and synthesis of the cardanol-based precursors 1-4 used for metathesis reactions.

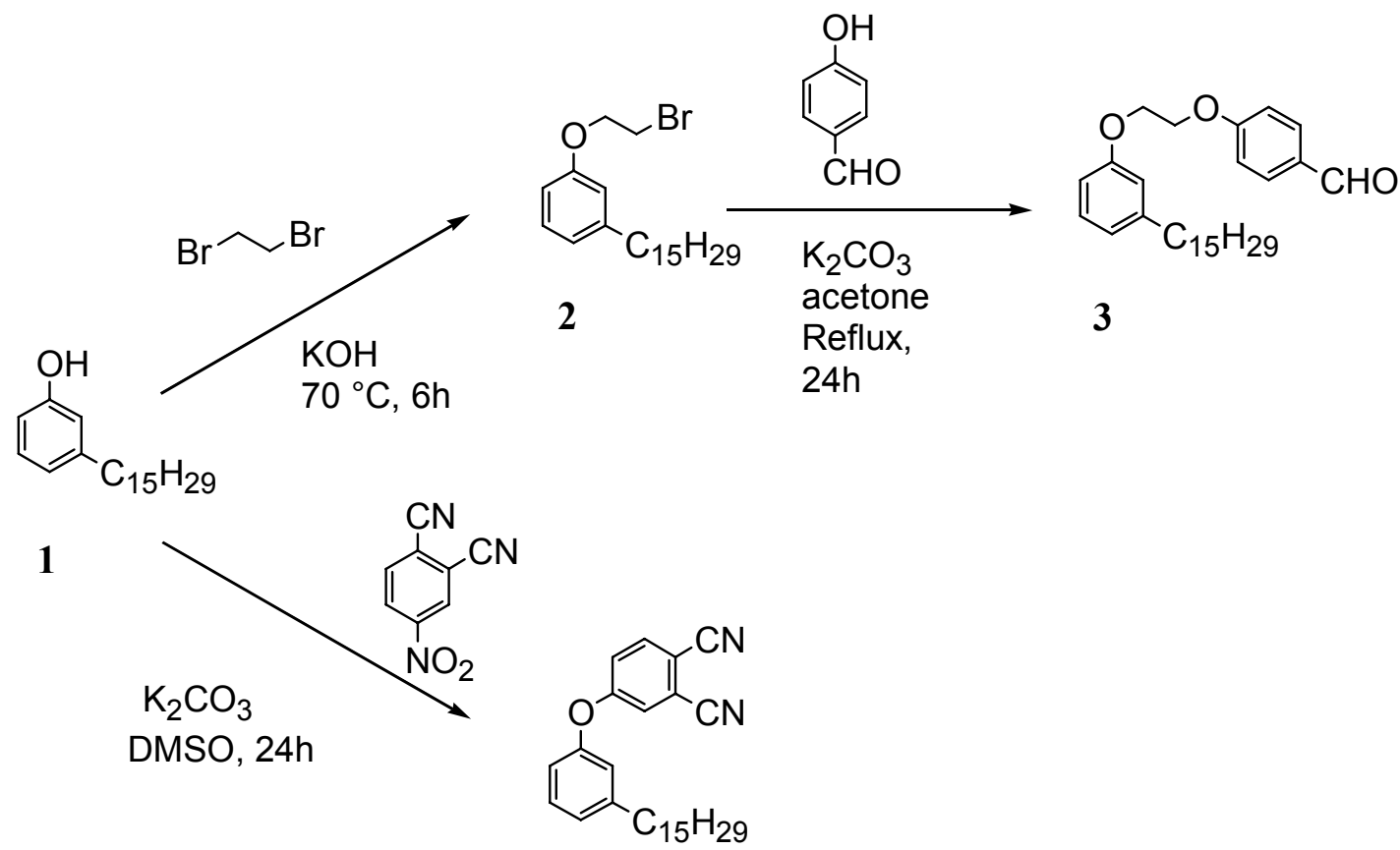


Scheme 2. Synthesis of the cardanol-based porphyrins 5-7 and fulleropyrrolidine 8 used for metathesis reactions.

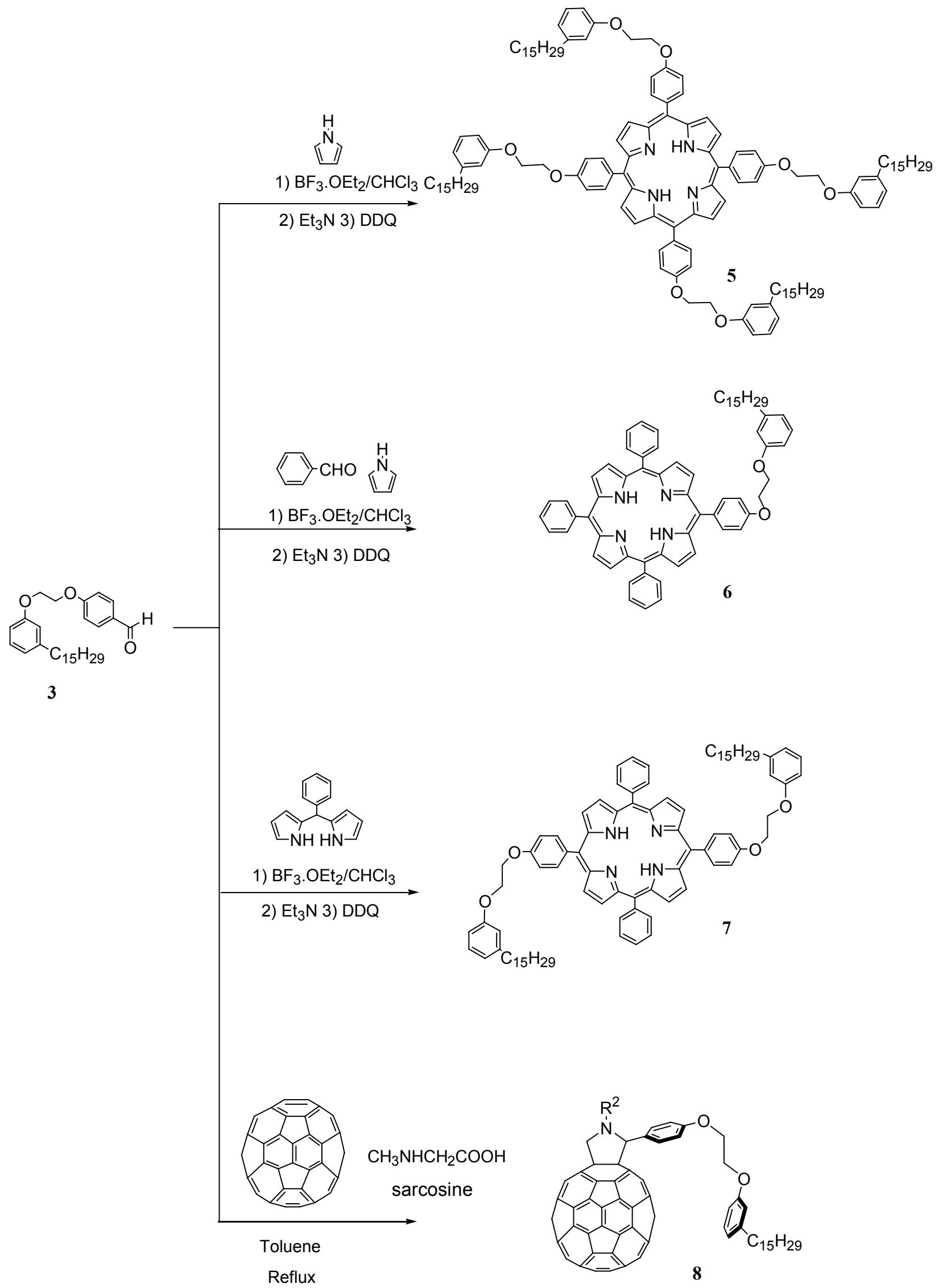


As summarized in Scheme 1, the compound 2 was prepared via the reaction of cardanol (1) with 1,2-dibromoethane in the presence of $\mathrm{KOH}$ at $70{ }^{\circ} \mathrm{C}$ for $6 \mathrm{~h}$ and isolated in $70 \%$ yield [15]. Successively, 2 was reacted with 4-hydroxybenzaldehyde in the presence of anhydrous potassium carbonate in acetone under reflux for $30 \mathrm{~h}$ to afford 3 in $40 \%$ isolated yield. The compound 4 was prepared in $90 \%$ isolated yield by reacting 1 with 1,2-dicyano-4-nitrobenzene in DMSO in the presence of $\mathrm{K}_{2} \mathrm{CO}_{3}$ at room temperature for $24 \mathrm{~h}$ [16].

As shown in the Scheme 2, 4-[2-(3-(pentadeca-8-enyl) phenoxy)-ethoxy]benzaldehyde 3 was reacted with pyrrole, benzaldehyde or fullerene according to the methods reported in the literature $[3,15]$ in order to obtain cardanol-based porphyrins 5-7 and cardanol-based fulleropyrolidine $\mathbf{8}$ which can be used as starting materials for metathesis reactions.

In particular, cardanol-based porphyrin 5 was obtained by the reaction of $\mathbf{3}$ with pyrrole [15]; porphyrin 6 was synthesized by the acid-catalyzed condensation of $\mathbf{3}$ with pyrrole and benzaldehyde or with meso-phenyldipyrrolmethane [3].

The fulleropyrrolidine cardanol 8 was prepared by the cycloaddition of sarcosine ( $N$-methylglycine) in the presence of 3 and $\mathrm{C}_{60}$ in refluxing toluene under nitrogen atmosphere for $24 \mathrm{~h}$ [17].

\section{Metathesis on Cardanol and Its Hybrid Derivatives}

As mentioned previously, the olefin metathesis reaction is an organic reaction which offers the possibility to form new olefins [18-21]. Different commercially available ruthenium-catalysts, which are illustrated in Figure 3 and labelled according to their molecular weights $(\mathbf{C 6 2 7}, \mathbf{C 8 2 3}, \mathbf{C 8 0 1}$, C848), have been used.

Figure 3. First- and second- generation of ruthenium-catalysts used for metathesis reactions.

First Generation

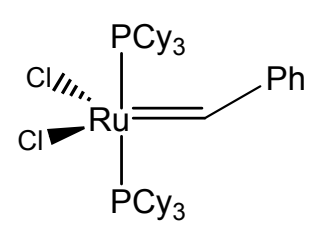

C823

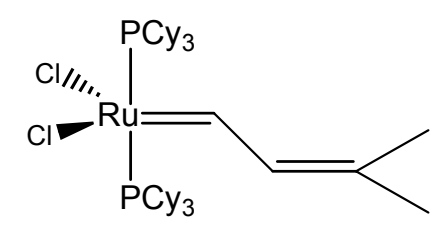

C801

\section{Second Generation}
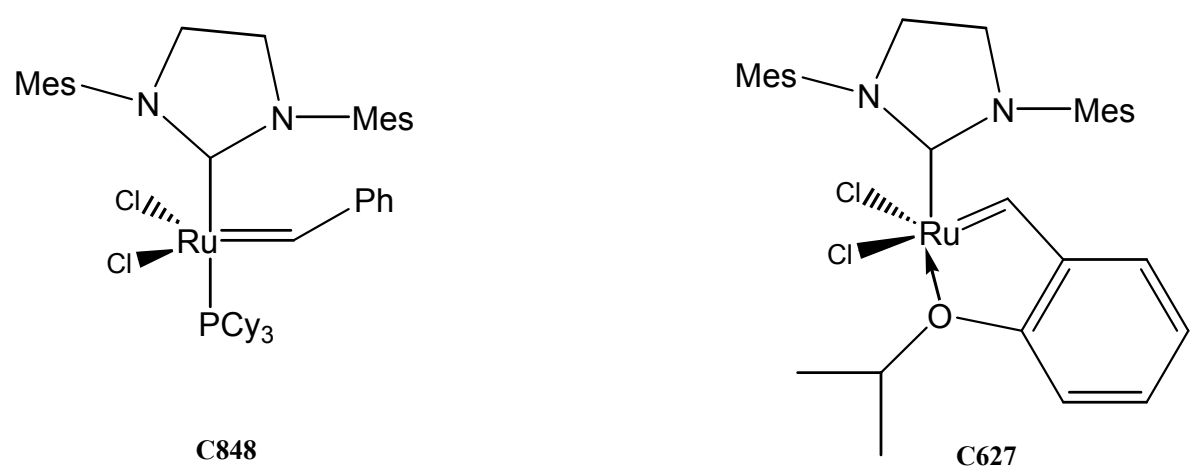

C627 
Initially, the mono-olefinic cardanol, 3-(pentadeca-8-enyl) phenol, was used as the starting material to prepare, using a Hoveyda-Grubbs' catalyst (Scheme 3) [22].

Scheme 3. Metathesis reaction involving cardanol 1 and its derivatives 2-4.

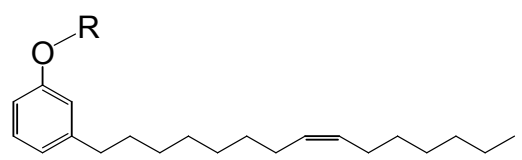

1-4

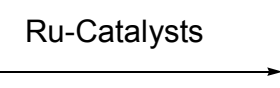

9-12

$+$

The metathesis reaction was then performed with other cardanol-based substrates to prepare the new derivatives listed in Table 1. The best metathesis conditions resulted used $2 \mathrm{mmol}$ of $\mathbf{1}$, and $5 \mathrm{~mol} \%$ of catalyst $\mathbf{C 6 2 7}$ in dichloromethane $(1.2 \mathrm{~mL})$ at $40{ }^{\circ} \mathrm{C}$ for $45-87 \mathrm{~h}$ under $\mathrm{N}_{2}$ atmosphere.

Table 1. Metathesis performed on cardanol 1 and cardanol derivatives 2-4.

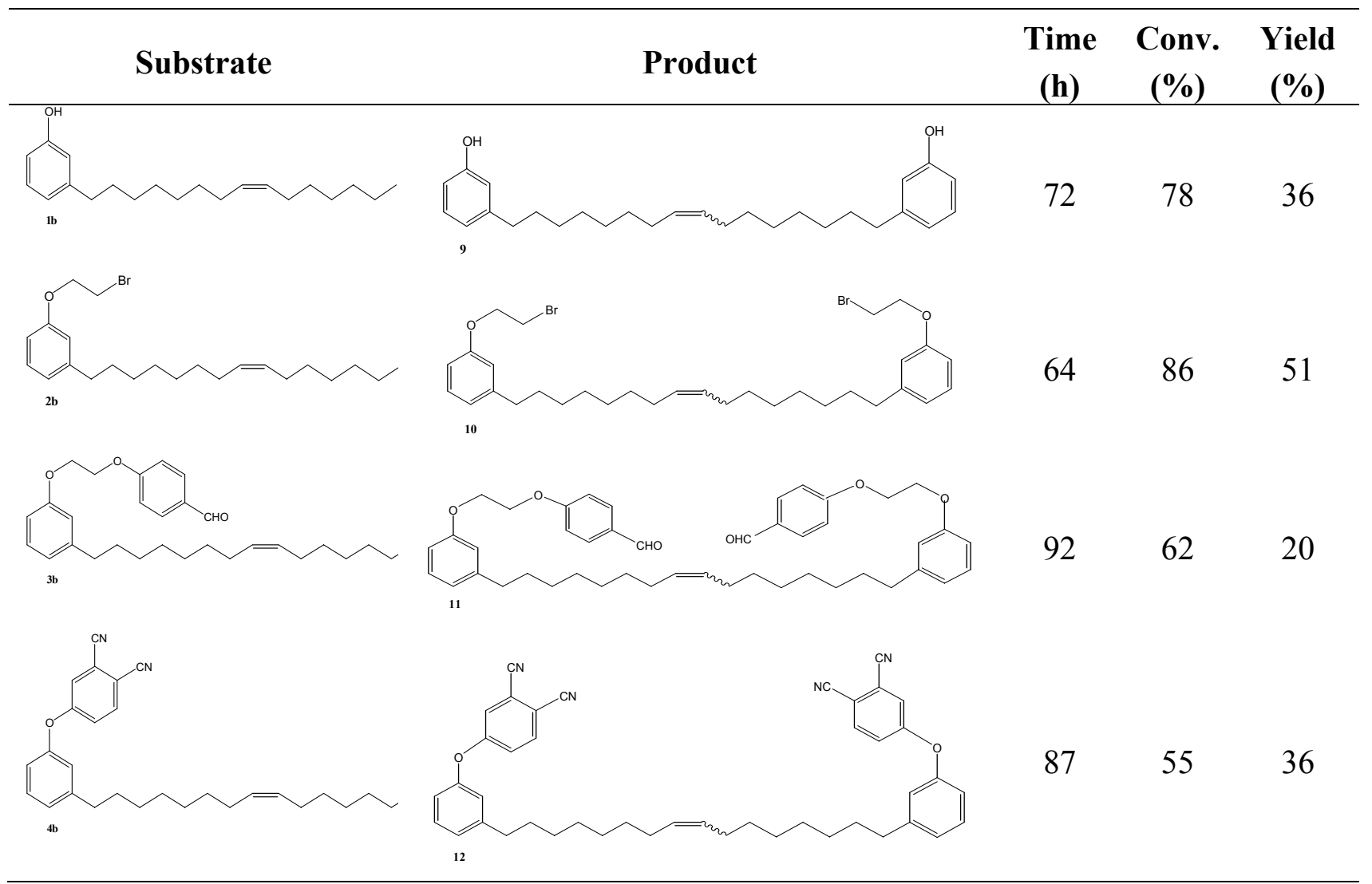

Reaction conditions: Starting material (1.0 mmol), catalyst C627 (2 mol \%); dichloromethane $(1.67 \mathrm{M})$. The reaction mixture was refluxed under nitrogen atmosphere.

In all cases, the conversion of 1-4 into 9-12 reached only $42 \%-65 \%$ (isolated yields). This was attributed to the reaction's reversibility $[20,23,24]$. All products were formed as a mixture of $Z$ - and $E$-isomers, in which $Z$-isomers were dominant according with the results reported by Meek et al. [25]. 
Subsequently, metathesis reactions were applied on cardanol in the presence of commercial olefins bearing $-\mathrm{COOH}$ and $-\mathrm{COOEt}$ moieties in order to prepare new cardanol-based carboxylic acid- (15) and ester-type (16) derivatives (Table 2) [26,27].

Table 2. Cross-metathesis reaction involving cardanol.

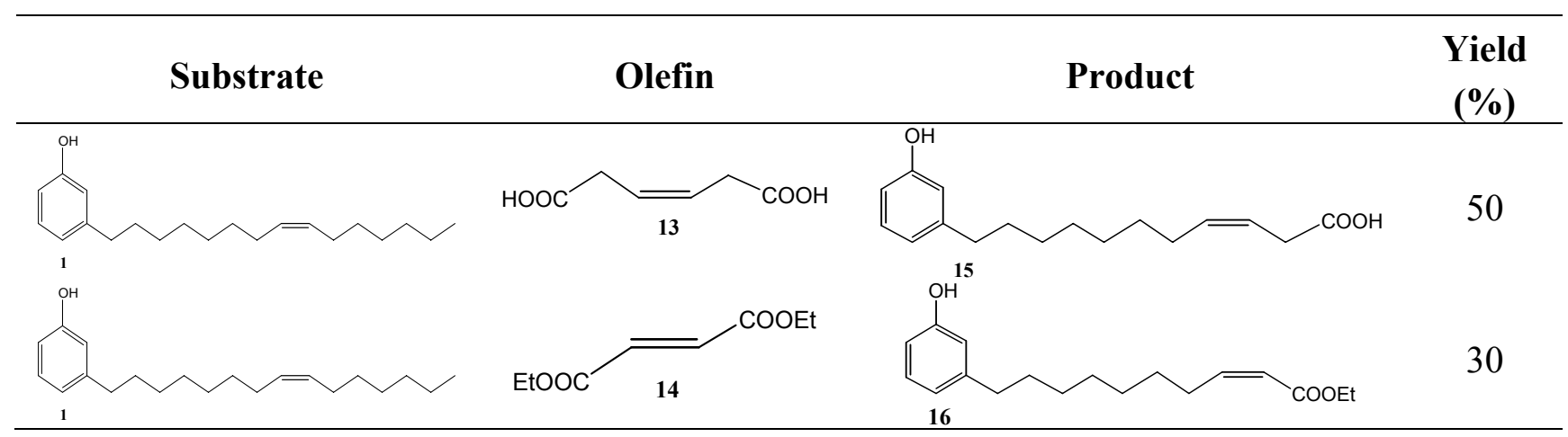

Reaction conditions: Substrate 1 (3.0 mmol), substrate 13 (or 14) $(3.0 \mathrm{mmol})$, C627 catalyst (5 mol\%); dichloromethane $(15 \mathrm{~mL})$. The reaction mixture was stirred under reflux in an oil bath.

In 2006, the preparation and characterization of new hybrid cardanol-based meso-tetraarylporphyrins bearing unsaturated chains were reported [15]. Metathesis reactions were then carried out on these porphyrins in order to prepare new cardanol-based products with different chemical and physical properties [15].

In 2009, new tetracardanol-based porphyrins were prepared, and an evaluation of an intra- or intermolecular metathesis process was investigated [28]. On one of these compounds, intramolecular metathesis was performed in dichloromethane and in the presence of $\mathrm{Ti}\left(\mathrm{O}^{i} \mathrm{Pr}\right)_{4}$ and Grubbs catalyst, involving two or all four double bonds of porphyrin's structure (Scheme 4). Two different products were isolated, one bearing a double-bridged moiety (compound 17), the other having two free alkyl chains (compound 18) [16].

Scheme 4. Metathesis reaction involving the cardanol based porphyrin 5.
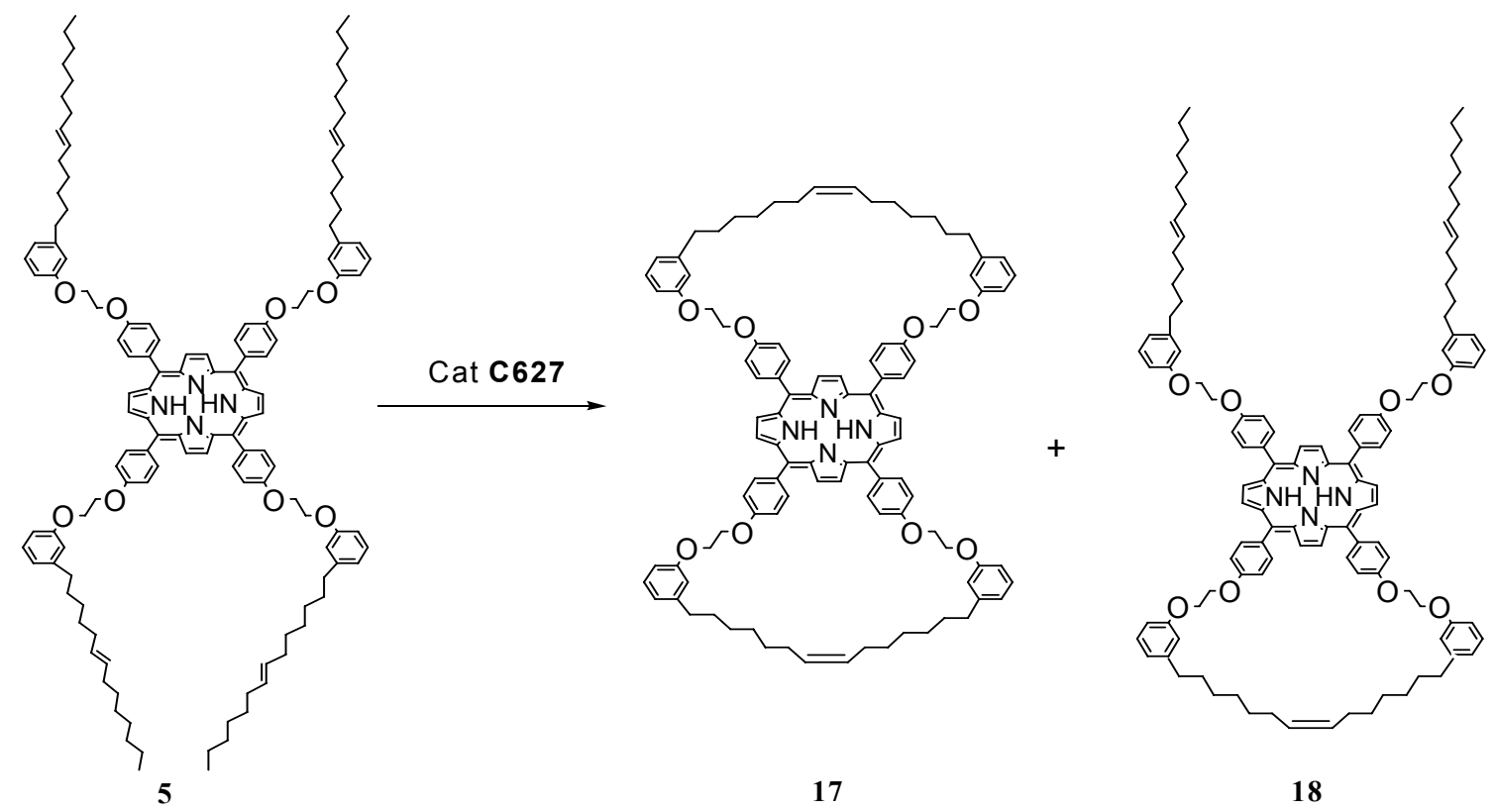
The ${ }^{1} \mathrm{H}-\mathrm{NMR}$ and LC-MS spectroscopic characterization of such compounds proved are in agreement with the proposed structure. It was possible to observe that the triplet at $0.9 \mathrm{ppm}$ of the methyl protons present in $\mathbf{5}$ disappeared in $\mathbf{1 7}$ because of the double-bridged porphyrin-porphyrin structure (Scheme 4). In contrast, this triplet was present in the ${ }^{1} \mathrm{H}-\mathrm{NMR}$ spectrum of $\mathbf{1 8}$. When the metathesis reaction was performed on the porphyrin derivative $\mathbf{Z n - 5}$, which contains only one cardanol moiety, an inter-molecular coupling occurred to produce 2Zn-19 (Scheme 5) [28]. The linking of porphyrin molecules by covalent bonds can give rise to stable, multi-porphyrin architectures and well-defined arrays, and this is a very good way for creating novel molecular wires, light-harvesting systems, energy transduction devices for molecular recognition and many other applications [29].

Scheme 5. Metathesis reaction involving the cardanol-based zinc porphyrin $\mathrm{Zn}-5$.

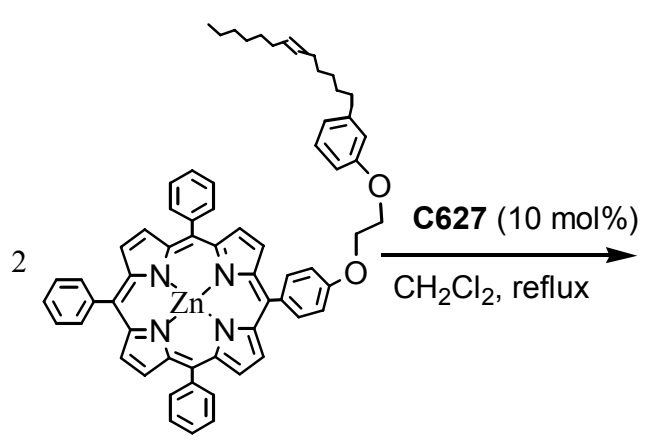

Zn-5

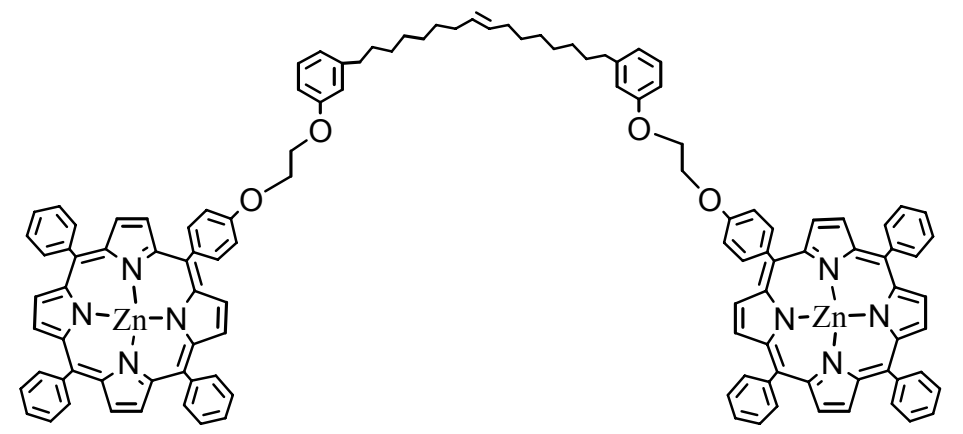

2Zn-19

The route by which the zinc compound 2Zn-19 was prepared is depicted in Scheme 5. The compound 2Zn-19 was isolated in 35\% yield [28]; it was successively de-metallated to obtain the non-metallic compound 20 (Scheme 6).

Scheme 6. Metathesis reaction involving the cardanol based zinc porphyrin 2Zn-19.

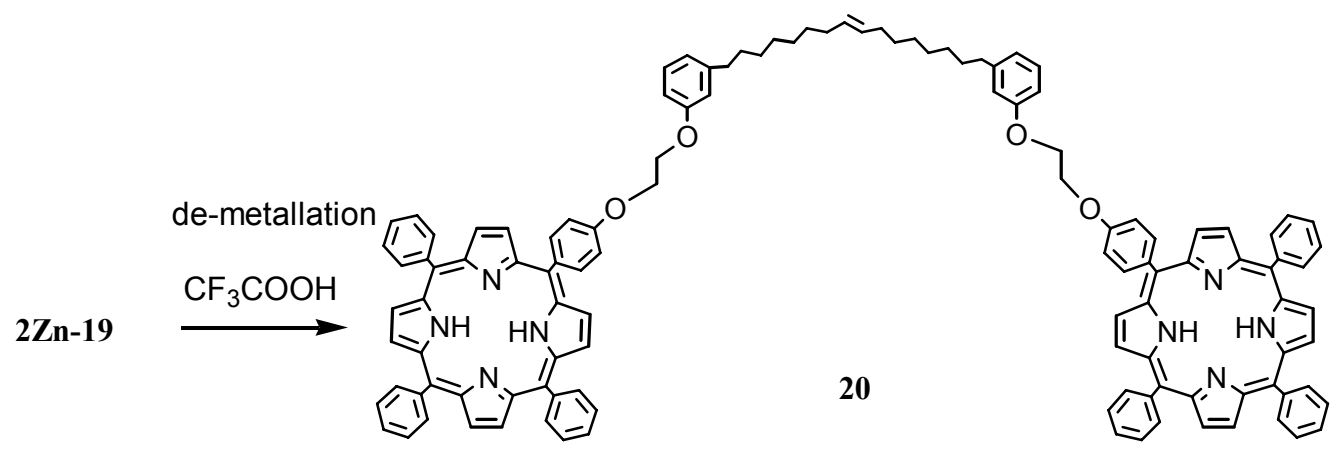

In the case of porphyrin derivatives with two symmetric cardanol moieties, 6 and $\mathbf{Z n - 6}$, using catalyst C627, produced the ring-closed products $\mathbf{2 1}$ and Zn-21, respectively in $\mathbf{2 0}$ and 30\% yields (Scheme 7) [28]. 
Scheme 7. Metathesis reaction involving the cardanol based porphyrins 6 and Zn-6.

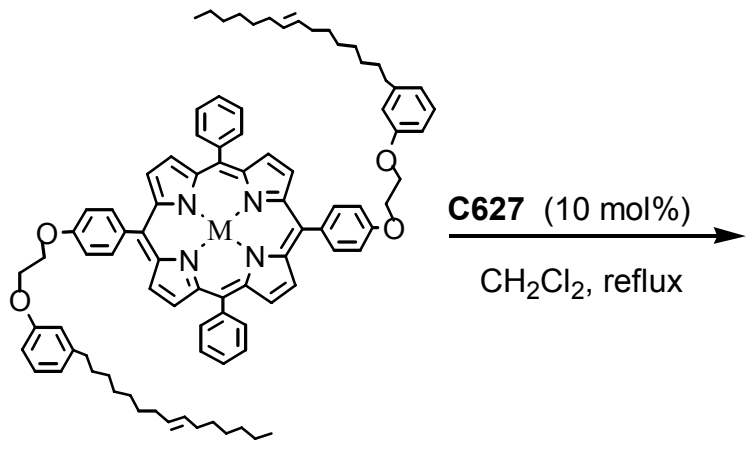

6, Zn-6

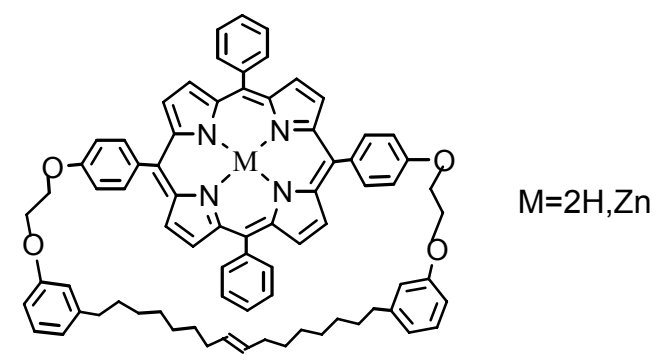

21, Zn-21

A few years ago, it was reported that new hybrid cardanol-based fulleropyrrolidines could be directly prepared via a three-component 1,3-dipolar cycloaddition reaction of fullerene $\left(\mathrm{C}_{60}\right)$ and $\mathrm{N}$-methyl glycine with various aldehydes in toluene. The reaction was found to proceed through the generation of azomethine ylides in situ [17,30]. So, in the same manner bis-fulleropyrrolidine 22 was prepared in $28 \%$ yield through a cycloaddition of the bis-azomethyne ylide in the presence of the cardanol based aldehyde precursors $\mathbf{1 1}$ and $\mathrm{C}_{60}$, as depicted in the Scheme 8.

Scheme 8. Preparation of the bis-fulleropyrrolidine 22 from the precursor 11.<smiles>CNCC(=O)O[Na]</smiles>

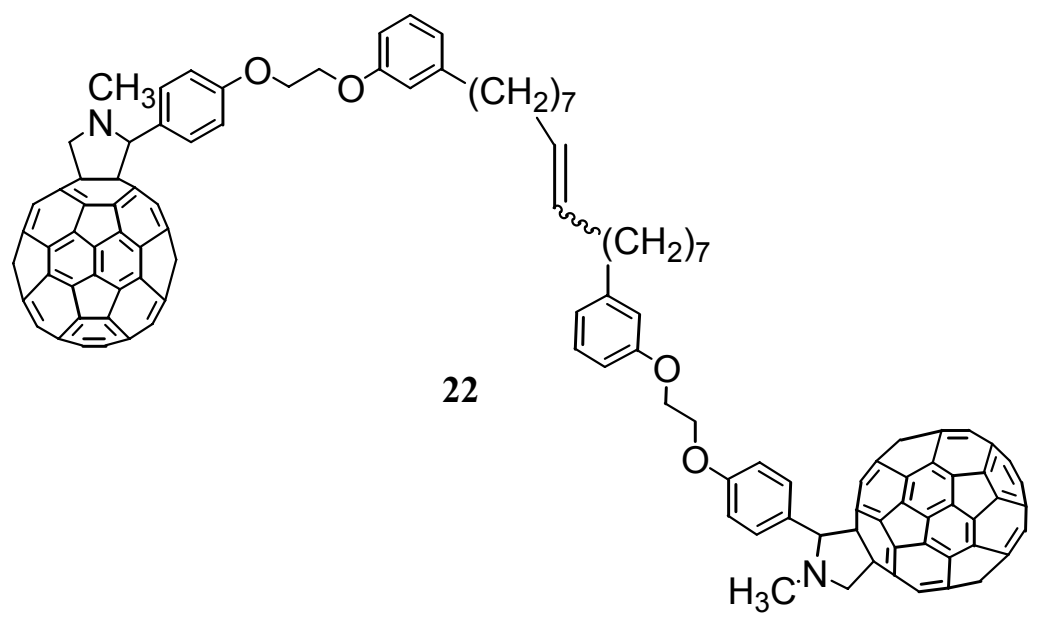


Alternatively, the bis-fulleropyrrolidine 22 could also be prepared according to Scheme 9.

Compound 22 was prepared in $30 \%$ yield through the metathesis reaction of the cardanol-based fulleropyrrolidine 8, which was obtained via the cycloaddition of $N$-methylglycine in the presence of the cardanol-based aldehyde precursors 3 using $\mathrm{C}_{60}$. In a typical reaction, $40 \mathrm{mg}(0.033 \mathrm{mmol})$ of fulleropyrrolidine $\mathbf{8}$ were dissolved in $21 \mathrm{~mL}$ of dichloromethane. Then, a solution of the catalyst $\mathbf{C 6 2 7}$ ( $0.42 \mathrm{mg}$ in $1.5 \mathrm{~mL}$ of $\mathrm{CH}_{2} \mathrm{Cl}_{2}, 0.02$ equiv.) was used to perform the metathesis reaction [17]. The crude product was purified with silica gel using toluene as the eluent.

Scheme 9. Preparation of the bis-fulleropyrrolidine 22 through homo-cross metathesis reaction of the fulleropyrrolidine $\mathbf{8}$ using $\mathbf{C 6 2 7}$ as catalyst.

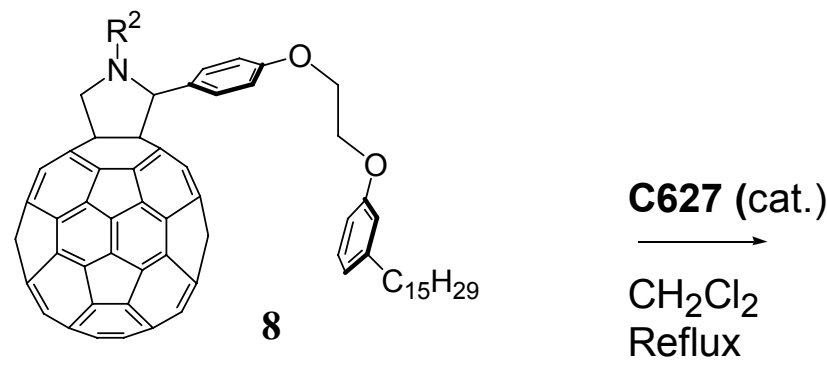

\section{Conclusions}

Cardanol a well-known by-product of the cashew industry has been successfully used as the starting material to perform olefin metathesis reactions. The olefin metathesis reaction is particularly convenient due to commercial availablility of many $\alpha$-olefins as renewable starting materials. In this paper, it has been shown that olefin metathesis reactions allow for the preparation of new cardanol-derived olefins and hybrid materials, combined with porphyrins and fullerenes, which are sometimes impossible to prepare via other methods.

\section{Acknowledgments}

The authors are grateful to University of Salento for financial support (ex. 60\%).

\section{References}

1. Tyman, J.H.P. Non-isoprenoid long chain phenols. Chem. Soc. Rev. 1979, 8, 499-537.

2. Tyman, J.H.P. Synthetic and Natural Phenols; Elsevier: Amsterdam, The Netherlands, 1996.

3. Mele, G.; Vasapollo, G. Fine chemicals and new hybrid materials from cardanol. Mini-Rev. Org. Chem. 2008, 5, 243-253.

4. Mazzetto, S.E.; Lomonaco, D.; Mele, G. Óleo Da Castanha De Caju: Oportunidades E Desafios No Contexto Do Desenvolvimento E Sustentabilidade Industrial. Quim. Nova 2009, 32, 732-741.

5. Lubi, M.C.; Thachil, E.T. Cashew nut shell liquid (CNSL) - A versatile monomer for polymer synthesis. Des. Monomers Polym. 2000, 3, 123-153.

6. Rodrigues, F.H.A.; Feitosa, J.P.A.; Ricardo, N.M.P.S.; de Franca, F.C.F.; Carioca, J.O.B. Antioxidant activity of cashew nut shell liquid (CNSL) derivatives on the thermal oxidation of synthetic cis-1,4-polyisoprene. J. Braz. Chem. Soc. 2006, 17, 265-271. 
7. Kim, Y.H.; Won, K.; Kwon, J.M.; Jeong, H.S.; Park, S.Y.; An, E.S.; Song, B.K. Synthesis of polycardanol from a renewable resource using a fungal peroxidase from Coprinus cinereus. J. Mol. Catal. B-Enzym. 2005, 34, 33-38.

8. Attanasi, O.A.; Berretta, S.; Favi, G.; Filippone, P.; Mele, G.; Moscatelli, G.; Saladino, R. Tetrabromo hydrogenated cardanol: Efficient and renewable brominating agent. Org. Lett. 2006, 8, 4291-4293.

9. Maffezzoli, A.; Calò, E.; Zurlo, S.; Mele, G.; Tarzia, A.; Stifani, C. Cardanol based matrix biocomposites reinforced with natural fibres. Comp. Sci. Tech. 2004, 64, 839-845.

10. Calò, E.; Maffezzoli, A.; Mele, G.; Martina, F.; Mazzetto, S.E.; Tarzia, A.; Stifani, C. Synthesis of a novel cardanol-based benzoxazine monomer and environmentally sustainable production of polymers and bio-composites. Green Chem. 2007, 9, 754-759.

11. Bhunia, H.P.; Jana, R.N.; Basak, A.; Lenka, S.; Nando, G.B. Synthesis of polyurethane from cashew nut shell liquid (CNSL), a renewable resource. J. Polym. A-Poly. Chem. 1998, 36, 391-400.

12. Coletta, M.; Filippone, P.; Fiorucci, C.; Marini, S.; Mincione, E.; Neri, V.; Saladino, R. A new and efficient synthesis of ortho- and para-benzoquinones of cardanol derivatives by the catalytic system $\mathrm{MeReO}_{3}-\mathrm{H}_{2} \mathrm{O}_{2}$. J. Chem. Soc. Perkin Trans. 1 2000, 581-586.

13. Amorati, R.; Pedulli, G.F.; Valgimigli, L.; Attanasi, O.A.; Filippone, P.; Fiorucci, C.; Saladino, R. Absolute rate constants for the reaction of peroxyl radicals with cardanol derivatives. J. Chem. Soc. Perkin Trans. 2 2001, 2142-2146.

14. Mele, G.; Del Sole, R.; Vasapollo, G.; García-López, E.; Palmisano, L.; Mazzetto, S.E.; Attanasi, O.A.; Filippone, P. Polycrystalline $\mathrm{TiO}_{2}$ impregnated with cardanol-based porphyrins for the photocatalytic degradation of 4-nitrophenol. Green Chem. 2004, 6, 604-608.

15. Guo, Y.C.; Xiao, W.J.; Mele, G.; Martina, F.; Margapoti, E.; Mazzetto, S.E.; Vasapollo, G. Synthesis of new meso-tetraarylporphyrins bearing cardanol and further transformation of the unsaturated chains. J. Porphyr. Phtalocya. 2006, 10, 1071-1079.

16. Attanasi, O.A.; Del Sole, R.; Filippone, P.; Mazzetto, S.E.; Mele, G.; Vasapollo, G. Synthesis of novel cardanol based porphyrins. J. Porphyr. Phtalocya. 2004, 8, 1276-1284.

17. Attanasi, O.A.; Mele, G.; Filippone, P.; Mazzetto, S.E.; Vasapollo, G. Synthesis and characterization of novel cardanol based fulleropyrrolidines. ARKIVOC 2009, VIII, 69-84.

18. Trnka, T.M.; Grubbs, R.H. The development of $\mathrm{L}_{2} \mathrm{X}_{2}$ RudCHR olefin metathesis catalysts: An organometallic success story. Acc. Chem. Res. 2001, 34, 18-29.

19. Herrmann, W.A. Heterocyclic carbenes: A new concept in organometallic catalysis. Angew. Chem. Int. Ed. 2002, 41, 1290-1309.

20. Grubbs, R.H. Olefin metathesis. Tetrahedron 2004, 60, 7117-7140.

21. Choi, T.L.; Chatterjee, A.C.; Grubbs, R.H. Synthesis of a, $\beta$-unsaturated amides by olefin cross-metathesis. Angew. Chem. Int. Ed. 2001, 40, 1277-1279.

22. Guo, Y.C.; Mele, G.; Martina, F.; Margapoti, E.; Vasapollo, G.; Xiao, W.J. An efficient route to biscardanol derivatives and cardanol-based porphyrins via olefin metathesis. J. Organomet. Chem. 2006, 691, 5383-5390.

23. Astruc, D. The metathesis reactions: From a historical perspective to recent developments. New J. Chem. 2005, 29, 42-56. 
24. Grubbs, R.H. Olefin-metathesis catalysts for the preparation of molecules and Materials. Angew. Chem. Int. Ed. Engl. 2006, 45, 3760-3765.

25. Meek, S.J.; O’Brien, R.V.; Llaveria, J.; Schrock, R.R.; Hoveyda, A.H. Catalytic Z-selective olefin cross-metathesis for natural product synthesis. Nature 2011, 471, 461-466.

26. Martina, F. Synthesis and characterization of new derivatives from cardanol. Ph.D. Thesis, University of Salento, Lecce, Italy, 2008.

27. Vasapollo, G.; Mele, G.; Martina, F. University of Salento, Unpublished work, 2009.

28. Mele, G.; Li, J.; Margapoti, E.; Martina, F.; Vasapollo, G. Synthesis of novel porphyrins cardanol based via cross metathesis. Catal. Today 2009, 140, 37-43.

29. Handbook of Porphyrin Science-With Applications to Chemistry, Physics, Materials Science, Engineering, Biology and Medicine; Kadish, K.M., Smith, K.M., Guilard, R., Eds.; World Scientific Publishing Co.: Singapore, 2010; Volume 1-10.

30. Attanasi, O.A.; Del Sole, R.; Filippone, P.; Ianne, R.; Mazzetto, S.E.; Mele, G.; Vasapollo, G. Synthesis of fullerene cardanol derivatives. Synlett 2004, 5, 799-802.

(C) 2011 by the authors; licensee MDPI, Basel, Switzerland. This article is an open access article distributed under the terms and conditions of the Creative Commons Attribution license (http://creativecommons.org/licenses/by/3.0/). 